\title{
DUODENAL ULCERS WITH EXTENSIVE LIVER DAMAGE IN INFANT TWINS
}

\author{
BY \\ J. J. KEMPTON and MARTIN BODIAN \\ From the Children's Department, the Royal Berkshire Hospital, Reading, and the Department of Morbid Anatomy, The \\ Hospital for Sick Children, Great Ormond Street, London
}

(RECEIVED FOR PUBLICATION JULY 3, 1953)

Peptic ulcer in infancy was first described by Cruveilhier (1829-42) over a hundred years ago, and those who have described cases or series of cases in more recent years (Holt, 1913; Kennedy, 1933; Guthrie, 1942; White Franklin, 1942; Fisher, 1950), and others have usually emphasized the view that the condition may well occur more frequently than is generally supposed. Paterson (1922), however, was able to find only a hundred cases in the literature and only three cases, including two observed by himself, in this country. Most reported ulcers have been in the duodenum.

It seems probable that many cases in which small ulcerations are present will be missed unless a special search is made, and this is perhaps true in some cases of liver disease with haemorrhagic phenomena such as bleeding into the lumen of the gut, in which the exact site of the bleeding is not ascertained.

Haemorrhagic disease of the newborn may be a manifestation of erosion either in the duodenum, stomach or at the lower end of the oesophagus, which normally heals rapidly. In later infancy the clinical picture tends to be more complex and varied than in the newborn period. Many of the reported cases have presented as prolonged and obstinate feeding difficulty leading to a picture of marasmus in which a duodenal ulcer has been found at necropsy. Others have presented the clinical picture of pyloric stenosis in infants of 4 to 6 months or more. The history of pain related to meals does not appear until later childhood.

There are also the cases occurring at various ages in which ulceration appears to be related to cerebral damage or neoplasm, or to infected hydrocephalus, and finally there is the doubtful association with burns (Curling”s ulcer).

The association of liver disease with duodenal ulcer was noted by Guthrie in one of her cases in which there was hepatitis, and by White Franklin in the first case in his series in which the liver showed extensive and severe fatty change.
The two cases to be described are unusual in that they occurred at the same time in binovular twins, in an illness of sudden onset associated, as in White Franklin's case, with an extreme degree of liver damage.

\section{Case Reports}

Case 1. Jean A. was born on November 1, 1951, a premature twin.

Delivery was normal (birth weight $3 \mathrm{lb} .5 \mathrm{oz}$.) and feeding began on the third day. At the eighteenth day there was some abdominal distension and a little mucus in the stools, and the infant was given penicillin orally for four days. She made steady but slow progress after this, and was discharged from hospital on January 10, 1952, weighing $6 \mathrm{lb}$. $10 \mathrm{oz}$. Breast feeding had failed after the first three weeks, and the baby was taking 'ostermilk'. Home conditions were poor. The parents with two other children aged 10 and 11 and twins aged 18 months lived in a dilapidated agricultural cottage. The family was healthy and there was no family history of peptic ulcer. The progress of the newborn twins at home was satisfactory until February 20, 1952. The feeds had been increased normally and the mother had added a wheat starch cereal ('Neave's food') to the bottle feeds. On the afternoon of February 20, both twins seemed fretful and refused their feeds. They vomited several times and their stools became loose and green. The other twin, Shirley, became dehydrated and seriously ill and was admitted to hospital four days later but Jean, after 24 hours on saline feeds, seemed much better and normal feeding was gradually restored. She still vomited occasionally however and did not appear completely well, and on the night of February 26 she vomited several times and seemed fretful and in pain. The mother noticed a shrill and unnatural cry. She became suddenly very pale and collapsed, and died during the night. There was no jaundice. The body was sent into the Royal Berkshire Hospital the following morning, and a limited necropsy was performed. The organs were exsanguinated and the liver, in addition, was a pale yellow suggesting extensive fatty change. The brain was normal to naked-eye inspection. A large duodenal ulcer was found and the whole gut was filled with dark blood clot. The ulcer was punched out and was situated in the posterior wall of the first part of the duodenum. 


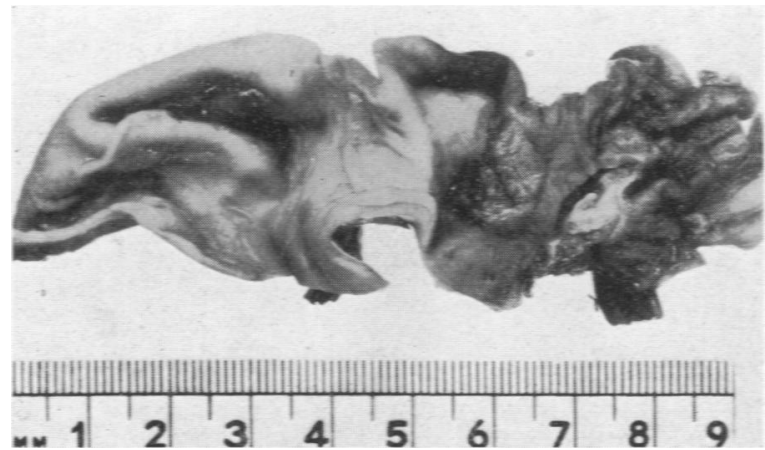

Fig. 1.- Photograph of uker in Jean A.

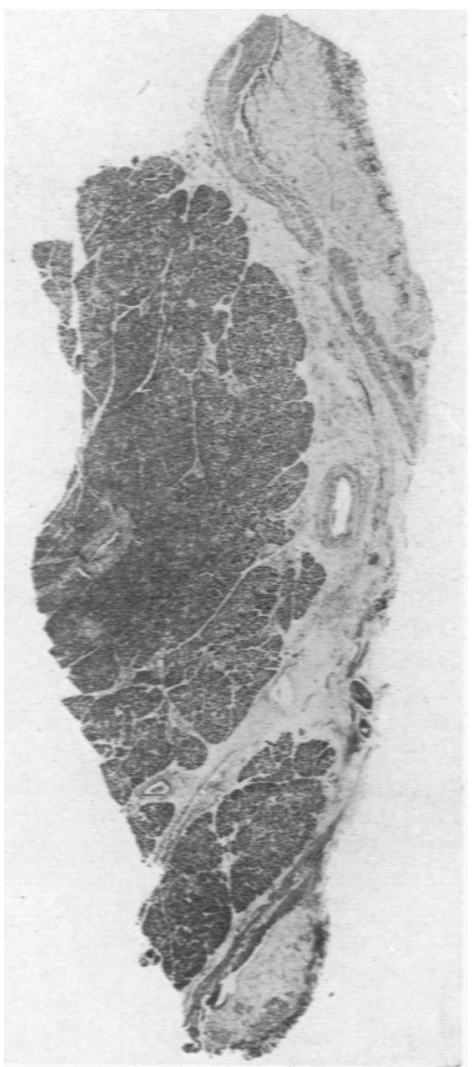

Fig. 2.- Section of ulcer in Jean A. $\times 7$.

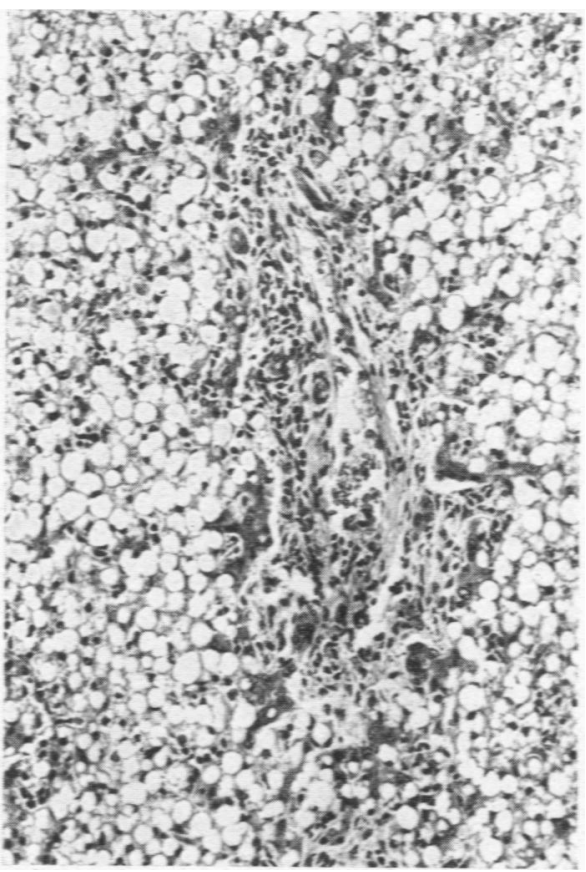

Fig. 3.-Section of liver in Jean A. 140.

It measured 1.2 by $1 \mathrm{~cm}$. in its maximum diameters, and the base was formed by the head of the pancreas (Fig. 1). Several small thrombosed vessels could be seen at the proximal margin. Microscopy showed the ulcer to be an acute lesion penetrating all coats except the serosa overlying the pancreas and forming the base of the craterlike lesion. There was a slight polymorphonuclear cell response to the tissue necrosis. Two partially thrombosed veins and a normal large artery could be seen at the base of the ukcer (Fig. 2). Microscopy of the liver showed a massive zonal necrobiosis with gross fatty change, except in narrow zones round the central veins where liver cells survived. The portal areas were slightly enlarged and showed mild infiltration by inflammatory cells. There was no evidence of extra- or intra-lobular bile retention (Fig. 3).

Case 2. Shirley A., the twin of Case 1, was a breech delivery (birth weight $4 \mathrm{lb}$.). Feeding began on the fourth day and was difficult at first. There was slight jaundice on the fifth day and one feed was vomited, the vomit containing a little blood. Some abdominal distension was noticed during the second and third weeks and feeding continued to be difficult. The birth weight was not regained until the fifth week. There was a transient conjunctival infection (Staph. aureus), for which oral penicillin was given during the third week, but it cleared up rapidly. After regaining her birth weight progress was steady, and on discharge with her sister on January 11 1952 , she weighed $6 \mathrm{lb}$. $10 \mathrm{oz}$. at the age of 10 weeks. 
Progress and feeding at home were satisfactory and parallel with that of her sister. 'Neave's food' was added to the 'ostermilk' bottle feeds by the mother when the babies were 3 months old, and the feeds were taken well. Fretfulness, refusal of feeds and vomiting began at the same time as in the twin, on February 20,1952. The baby was seen the next day by the family doctor and put on saline feeds for $\mathbf{2 4}$ hours, after which there seemed to be some improvement. There was no pyrexia. On again increasing feeds vomiting recurred and she was sent into hospital on February 24.

On examination she was pale and severely dehydrated. There was no jaundice. Stools were loose and watery and very frequent, and all fluid by mouth was vomited. The left ear drum was red and bulging but the rest of the respiratory tract seemed normal. Heart sounds were normal, and nothing abnormal could be felt in the abdomen. An intravenous drip of 1 in 5 normal saline with $5 \%$ glucose was set up and paracentesis performed on the left ear, and the baby was given penicillin and aureomycin, and her condition improved. However, blood appeared in the stools and vomit a few hours after admission, and within $\mathbf{2 4}$ hours both had the appearance of pure blood. Blood, $150 \mathrm{ml}$., was given when the baby appeared to be adequately rehydrated. Soon after admission a high-pitched and quite abnormal cry was noticed and lumbar puncture was performed; the fluid was normal in all respects. Stools and rectal swabs grew no pathogens. Four days after admission she had made some improvement and oral feeding was started again. The cry was still high-pitched and there were some abnormal limb movements. Feeding was slowly increased and the child improved steadily during the next week in which the stools returned to normal and there was only occasional slight vomiting. In view of the findings in the twin it was thought justifiable to attempt an $x$-ray investigation and some thin barium was given. This seemed to show some pylorospasm but no ulcer crater, and the child was put on 'eumydrin' before feeds. The following day the cry again became shrill and quite abnormal; there were neck stiffness, nystagmus, and twitching limb movements, and vomiting again began. She collapsed and died suddenly during the afternoon.

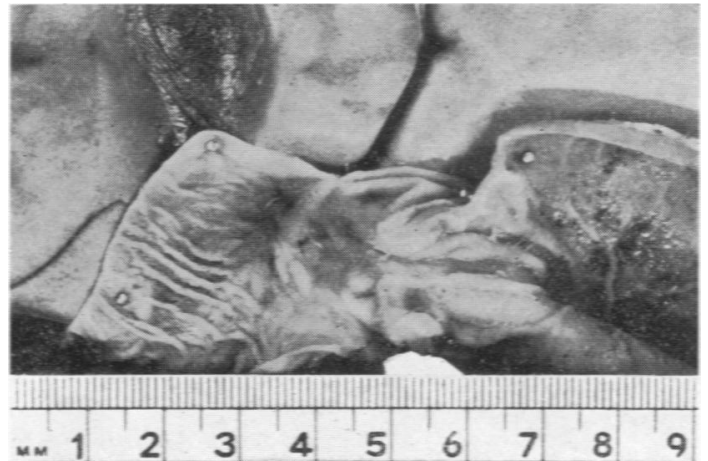

FIG. 4.-Photograph of uker in Shirley A. 
At necropsy a duodenal ulcer was found in the same position as in the twin (Fig. 4). It was of irregular shape and punched-out appearance and measured $1 \cdot 3$ by $1 \cdot 2$ $\mathrm{cm}$. in its maximum diameters. The base was formed by bile-stained necrotic debris. Microscopy showed a subacute ulcer penetrating the mucous and muscular coats, with evidence of some healing; between the necrotic base and the pancreas there was a fairly deep layer of granulation tissue with considerable fibroblastic activity and numerous new capillaries. No changes were seen in the larger arteries or veins (Fig. 5). The liver was a pale yellow. Sections of the liver showed diffuse cellular necrobiosis with gross fatty change. The portal areas displayed mononuclear cell and fibroblastic infiltration, and there was some early perilobular fibrosis, thin connective tissue strands linking adjacent portal areas (Fig. 6). There was slightly more reparative change in this liver than in that of the twin. Sections from the cerebral cortex, cerebellum, thalamus, hypothalamic region. lenticular nucleus, pons and medulla showed only some hyperaemia. The pituitary, adrenals, pancreas and spleen were normal to naked-eye inspection and on section. The kidneys on section showed congestion and mild fatty change in some cortical and medullary tubules, and slight calcium deposition in a few cortical tubules. The bronchi were normal. Sections from the lungs showed hyperaemia and focal collapse but no inflammatory changes. The stomach, jejunum, ileum and large intestines showed nothing significant to naked-eye or on microscopical examination.

\section{Discussion}

These 4-month-old twins died following an illness with diarrhoea and vomiting of obscure aetiology. Both had large duodenal ulcers and extensive liver damage. Jean died on the sixth day of illness and showed more acute changes and little evidence of the reparative processes seen both in the ulcer and in the liver of Shirley who survived for 12 days. There was nothing in the history or on subsequent enquiry to suggest any chemical poisoning, so that it is presumed that the intoxication was of infective origin.

The twins were binovular (appearance was dis- similar and there were two placentas) but the illness seems to have been identical and provided the unusual opportunity of observing in some detail what was essentially the same pathological process at two stages in its evolution. This has seemed to us to justify the placing on record of these cases.

It is of interest that in the experimental cincophen ulcer in dogs (Ivy, Grössman and Bachrach, 1950), liver changes occur-vacuolization and necrosis of the hepatic cells-which are strikingly similar to those in these babies. The mechanism which produces a cincophen ulcer is not completely understood. It is thought, however, that cincophen affects the detoxifying mechanism of the liver, particularly glucuronic acid conjugation. The depletion of glucuronic acid, which is an essential part of mucin, could lead to the formation of an ulcer. The formation of the cincophen ulcer can be prevented or retarded by the application of mucin, pectin or liver extract.

It is tentatively suggested that a similar mechanism may have been at work in producing the striking association of liver damage and duodenal ulceration in these twins with severe 'gastro-enteritis'. It is thought that in such cases treatment with mucin or pectin might be beneficial. In fatal cases, however, a careful search for the presence of erosions or ulcers in the gastro-intestinal tract should be made.

It is a pleasure to express our thanks and indebtedness to Dr. J. Mills, pathologist to the Royal Berkshire Hospital, in whose department the necropsies were carried out and to Dr. E. F. Chapman of Crowthorne, Berkshire, the family doctor.

\section{REFERENCES}

Cruveilhier, J. (1829-42). Anatomie Pathologique du Corps Humain, vol. 2. Paris.

Fisher. J. H. (1950). Amer. J. Dis. Child., 79, 50

Franklin, A. White (1942). Archives of Disease in Childhood, 17. 95 Guthrie, K. J. (1942). Ibid., 17. 82.

Holt, L. E. (1913). Amer. J. Dis. Child., 6, 381. Ivy, A. C., Grössman, M. I. and Bachrach, W. H. (1950). Peptic

Kennedy, R. L. J. (1933). J. Pediat., 2. 641.

Paterson, D. (1922). Lancet, 1, 63. 